\title{
Mitral Valve Replacement in a Patient with Porcelain Aorta after Previous Myocardial Revascularization
}

\author{
Ignazio Condello*, Giuseppe Speziale \\ GVM Care \& Research, Department of Cardiovascular Surgery, Anthea Hospital, Bari, Italy \\ *Corresponding author: ignicondello@hotmail.it
}

Received July 12, 2019; Revised August 18, 2019; Accepted August 27, 2019

\begin{abstract}
Redo cardiac surgery represents a clinical challenge due to a higher rate of perioperative morbidity and mortality. Mitral valve (MV) reoperations can particularly be demanding in patients with patent coronary grafts, previous aortic valve replacement, calcified aorta or complications following a previous operation. In this article we describe technique to manage systemic hyperkalemia in 68-year-old man who underwent bioprosthetic mitral valve replacement, already undergone coronary artery bypass grafting 13 years, come in our clinic to aggravated dyspnea caused by severe stenosis of the mitral valve. Because cross-clamping would have a high risk of stroke owing to severe calcification of the ascending aorta systemic hyperkalemia and continuous blood perfusion can guarantee adequate myocardial protection particularly in the case of patent grafts, decreasing potential lesions due to demanding clamp placing.
\end{abstract}

Keywords: calcified aorta, no-touch technique, systemic hyperkalemia, mitral valve replacement, cardiopulmonary by pass

Cite This Article: Ignazio Condello, and Giuseppe Speziale, "Mitral Valve Replacement in a Patient with Porcelain Aorta after Previous Myocardial Revascularization." American Journal of Medical Case Reports, vol. 7, no. 11 (2019): 277-279. doi: 10.12691/ajmcr-7-11-4.

\section{Introduction}

Aortic cross-clamping in patients with porcelain aorta is associated with high mortality and morbidity rates. In this case report, we show an alternative technique in a porcelain aorta patient with myocardial revascularization, without the aortic manipulation , use of hypothermia and ventricular fibrillation, through systemic hyperkalemia.

\section{Report of the Case}

\subsection{Patient Characteristics}

At the cardiac surgery division from Anthea hospital Gruppo Villa Maria, Bari, Italy; in June 2018, was admitted for elective cardiac surgery, a male patient of 68 years old , height $170(\mathrm{~cm})$, with a weight of $75(\mathrm{~kg})$. With diagnosis of mitral valvular stenosis transvalvular mean gradient $8 \mathrm{mmHg}$, the patient was subjected to myocardial revascularization in May 2005 for critical stenosis of the anterior descending coronary artery, treated with a left mammary artery implant. The ejection fraction estimated at echocardiography with the Simpson biplane method was $35 \%$ in 2018, absence of aortic insufficiency, at echocardiographic examination, was found a calcific ascending and thoracic aortic wall, during X-Ray and CT scan before surgery (Figure 1, Figure 2) [1]. Have not been found hemodynamically significant carotid stenosis . The patient did not have diabetes mellitus, renal failure, NYHA class II. Preoperative blood count values without significant alterations (Hemoglobin $11.5 \mathrm{~g} / \mathrm{dl}$, Creatinine $1.10 \mathrm{mg} / \mathrm{dl}$ ). The patient was a candidate for mitral valve replacement surgery with a Euroscore II 2.5\%, and underwent a Mini-Mental State Examination, before the procedure he reported an index of 28, an expression of cognitive normality [2].

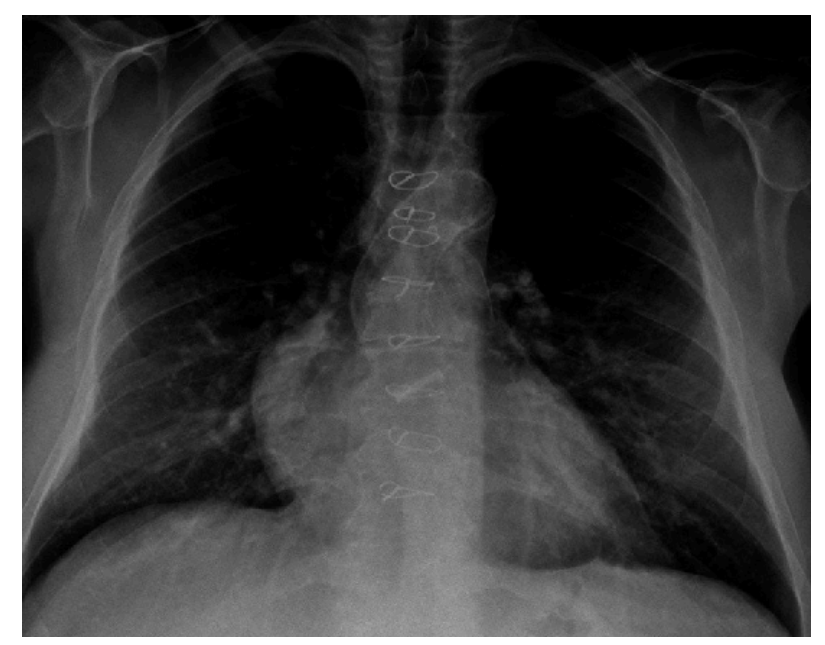

Figure 1. Preoperative chest radiography showed a hyperdense aspect of the ascending aorta and aortic wall 

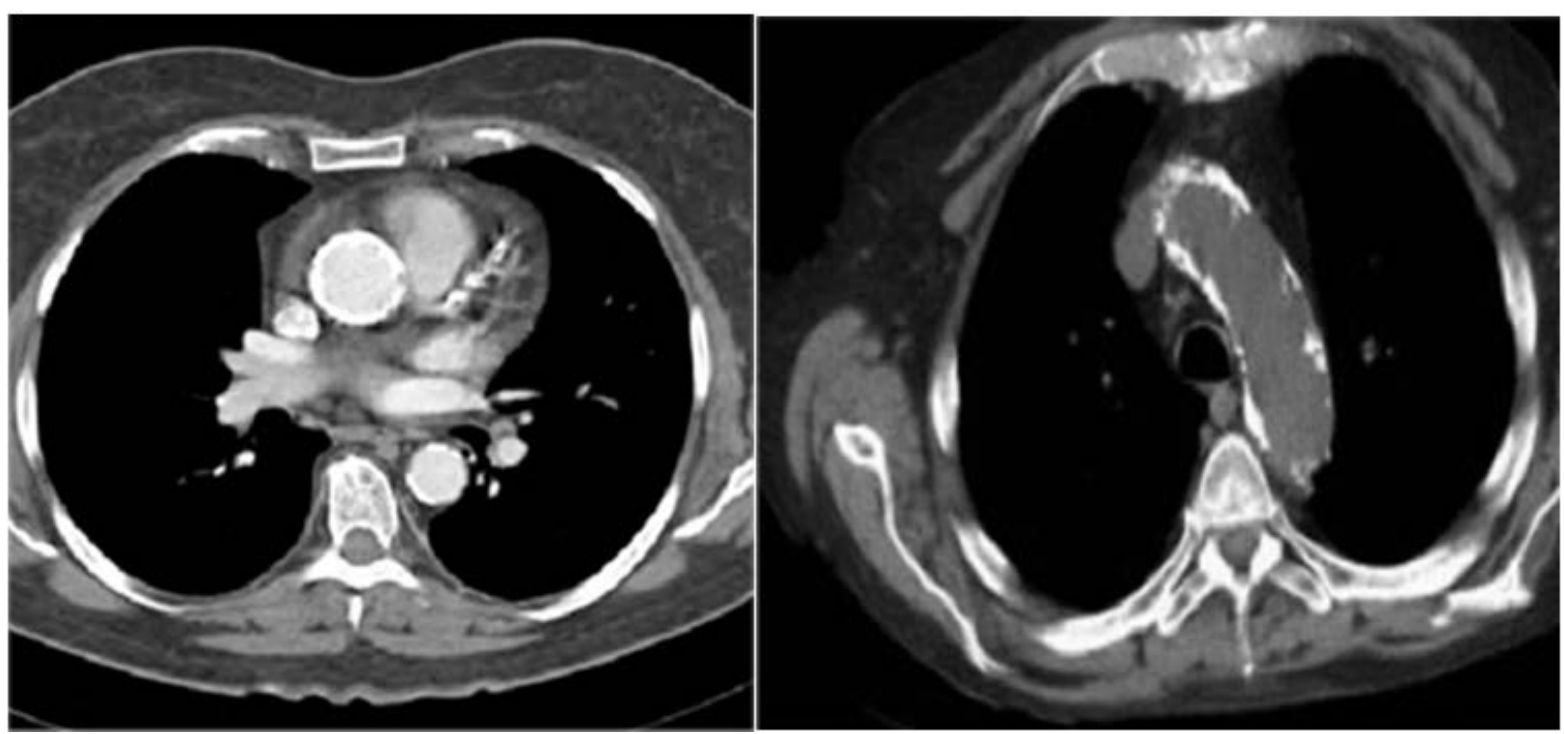

Figure 2. Computed-tomographic $\mathrm{C}$ scan with Porcelain aorta before the procedure

\subsection{Surgical technique}

A median sternotomy was performed; the detachment of the adherent tissues has been done with a beating heart. During the exploration phase by the first operator of the ascending aorta tract, a calcified aorta in the ascending portion was highlighted, strategically it was decided not to isolate the left internal mammary artery. After heparin administration an arterial cannulation was performed, with a 22 Fr EOPA 3D medtronic cannula in the proximal section of the aortic arch, and a selective cannulation of the superior vena cava medtronic venous Pacifico cannula $18 \mathrm{Fr}$, and the inferior vena cava was medtronic venous cannula $32 \mathrm{Fr}$. Cardiopulmonary bypass was performed at $35^{\circ} \mathrm{C}$ nasopharyngeal temperature, using goal directed perfusion as a protocol, an Delivery of oxygen was $\left(\mathrm{DO}_{2} / \mathrm{BSA}\right.$ mean $\left.321 \mathrm{ml} / \mathrm{min} / \mathrm{m}^{2}\right)$, [3,4] cardiac index of $2,5 \mathrm{l} / \mathrm{min} / \mathrm{m}^{2}$, and the $\mathrm{pH}$ management technique was alpha stat. The potassium level (mmol / L of Blood gas Test) was used as nadir for the management of asystole with hyperkalemia [5], the potassium level during the first Blood Gas Test was $4.9 \mathrm{mmol} / \mathrm{l}$. Were administered bolus 35 meq of $\mathrm{K}^{+} \mathrm{Cl}^{-}$, in the extracorporeal circulation through, the same dosage used for myocardial protection (Calafiore et al.) [6,7]. The diastolic release of the heart with asystole was obtained immediately, the Blood Gas test reported $7.9 \mathrm{mmol} /$ liter of potassium; serial B.G.T were performed every 10 min to maintain the level, with a slow infusion of 20 meq of $\mathrm{K}^{+} \mathrm{Cl}^{-}{ }_{(2 \mathrm{meq} / \mathrm{ml})}$. Four minutes after asystole, the surgery replacement procedure was started, with surgical access for the left conventional atriotomy, the aortic valve did not present insufficiency during the procedure, this allowed this to the surgeon to have a good surgical vision, the stenotic valve was replaced with the traditional technique, has been used the Medtronic Hancock TM II Model T510C biological valve prosthesis size $25 \mathrm{~mm}$ (Figure 3), CO2 was administered with a $2.5 \mathrm{l} / \mathrm{min}$ flow in the field during the procedure; for the prophylaxis of air embolism. Bispectral index (bis) monitor remained at the value of 38 no modification of anesthesia was necessary [8], during bolus administration of $\mathrm{K}^{+} \mathrm{Cl}$ and throughout the procedure. The asystole was maintained for 43 minutes (Figure 1), the replacement was
36 minutes, before the left atrium was closed, a endocavitary aspirator was inserted; at the same time the heating of the patient was started, and they were administered 10 units of insulin actrapid ${ }^{\circledR}$; to lower potassium levels with $30 \mathrm{ml}$ of $33 \%$ glucose solution. The potassium level returned from $7.8 \mathrm{mmol} / \mathrm{l}$ to $5.3 \mathrm{mmol} / \mathrm{l}$, the glycemia from $220 \mathrm{mg} / \mathrm{dl}$ to $170 \mathrm{mg} / \mathrm{dl}$ after 13 minutes [9]. Resumption sinus rhythm of 63 beats per minute that was guided with pace maker atrial, weaning was guided with transesophageal echocardiography in middle esophageal projection for air removal, using vent and Trendelenburg position, the removal of the air lasted 4 minutes, and subsequently weaning from the extracorporeal circulation occurred [10]. The overall duration of the cardiopulmonary bypass was 54 minutes $[11,12,13]$. The result was comparable to conventional mitral valve replacement intervention, with the use of cross-clamping and the administration of myocardial protection in terms of results, for myocardial ischemic markers TnT (ng/L), (1.8); and in the administration of blood products only one bag of RBC during I.C.U stay and in duration of mechanical ventilation 8 hours.

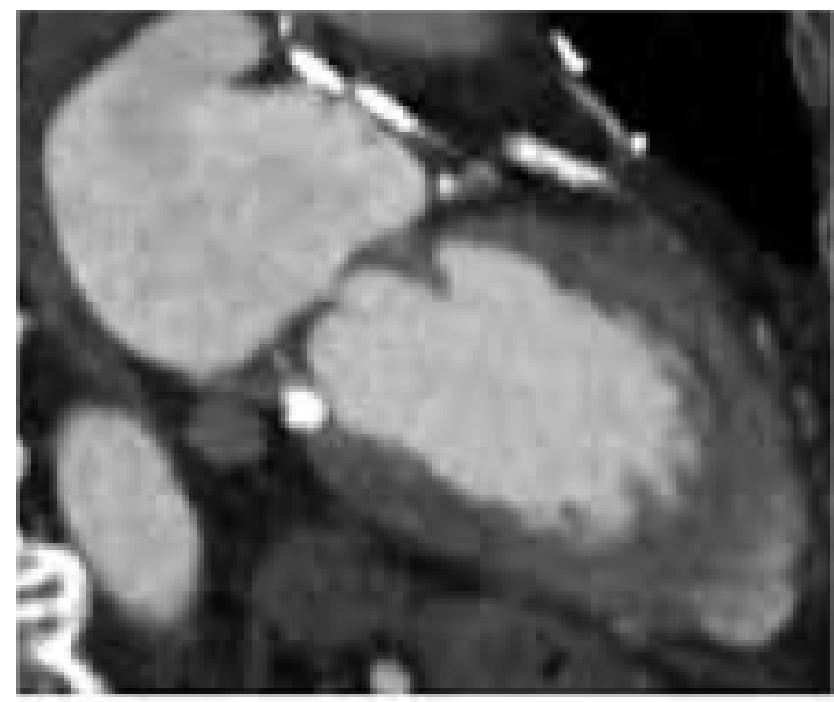

Figure 3. Computed-tomographic C scan with Mitral Valve Replacement after procedure 
Absence of complications and neurological sequelae attributable to gaseous embolism, no significant variability was reported at the follow-up for 24, 48 hours at seven days and at 20 days at the Mini-Mental State Examination (average index 27), no marker of myocardial damage, no inotropic support was used and renal function remained preserved, creatinine $(0.98 \mathrm{mg} / \mathrm{dl})$.

\section{Discussion}

Although the outcomes of reoperative cardiac surgery have improved, reoperative mitral valve surgery still poses a higher risk of mortality and post- operative complications, such as stroke, prolonged ventilation, and reoperation for bleeding, than first- time mitral valve surgery. The present case had several risk factors for redo mitral valve replacement. First, there was a high risk of stroke due to the heavily calcified ascending aorta, which prohibited us from performing routine ascending aortic cannulation and Aortic Cross Clamp. Second, the patent bypass graft increased the risk of reoperation due to the possibility of injury during reentry and during exposure of the internal thoracic artery grafts, which should be clamped during cardioplegic arrest. Due to these concerns, clampless surgery under systemic hypercalemia was planned.

\section{Conclusion}

This technique of cardiac arrest with systemic hyperkalemia in Redo, should reduce the incidence of stroke risk reported in the literature on the MVR under fibrillary arrest, avoid the use of bodily hypothermia, and circulatory arrest [14]. In conclusion, a systemic hypercaliemia approach with a clampless technique combined might be a viable option for patients who need valve surgery, have a porcelain ascending aorta, and are at risk of embolic stroke.

\section{References}

[1] Desai MY, Cremer PC, Schoenhagen P. Thoracic Aortic Calcification: Diagnostic, Prognostic, and Management Considerations. JACC Cardiovasc Imaging. 2018 Jul; 11(7): 1012-1026.
[2] Folstein MF, Folstein SE, McHugh PR, "Mini-mental state". A practical method for grading the cognitive state of patients for the clinician, in Journal of psychiatric research, vol. 12, $\mathrm{n}^{\circ} 3,1975$, pp. 189-98.

[3] De Somer $\mathrm{F}^{1}$, Mulholland JW, Bryan MR, Aloisio T, Van Nooten GJ, Ranucci M. O2 delivery and CO2 production during cardiopulmonary bypass as determinants of acute kidney injury: Time for a goal-directed perfusion management? Crit Care. 2011 Aug 10; 15(4): R192.

[4] De Somer F. Optimization of the perfusion circuit and its possible impact on the inflammatory response. J Extra Corpor Technol. 2007 Dec; 39(4): 285-8.

[5] Ramanathan $\mathrm{T}^{1}$, Shekar P, Fitzgerald D, Ghanta RK, Aranki SF, Cohn LH, Chen EP, Chen FY. Systemic hyperkalemia for cardiac arrest on CPB with or without cross-clamping. J Card Surg. 2008 Nov-Dec; 23(6): 611-3.

[6] Calafiore AM, et al; Intermittent Antegrade Warm Blood Cardioplegia: What Is Next? Thorac Cardiovascular Surg. 2019 Mar 5.

[7] Maloney JV, Nelson RL. Myocardial preservation during cardiopulmonary bypass: an overview. J Thorac Cardiovasc Surg. 70(6): 1040-50.

[8] Kertai $\mathrm{MD}^{1}$, Whitlock EL, Avidan MS.Brain monitoring with electroencephalography and the electroencephalogram-derived bispectral index during cardiac surgery. Anesth Analg. 2012 Mar; 114(3): 533-46.

[9] Armando Coca, Ana Lucia Valencia, Jesus Bustamante, Alicia Mendiluce, Jürgen Floege. Hypoglycemia following intravenous insulin plus glucose for hyperkalemia in patients with impaired renal function PLoS One. 2017; 12(2): e0172961.

[10] Lou S, Ji B, Liu J, Yu K, Long C. Generation, detection and prevention of gaseous microemboli during cardiopulmonary bypass procedure. Int J Artif Organs. 2011 Nov; 34(11): 1039-51.

[11] Khalpey, Z., Dekkers, R.J., Nauta, F.J., and Shekar, P. Warm beating heart with deep hypothermic circulatory arrest: a technique for an unclampable aorta with aortic valve regurgitation. J Thorac Cardiovasc Surg. 2012; 144: 731-732.

[12] Byrne, J.G., Aranki, S.F., and Cohn, L.H. Aortic valve operations under deep hypothermic circulatory arrest for the porcelain aorta: "no-touch" technique. Ann Thorac Surg. 1998; 65: 1313-1315.

[13] Aranki, S.F., Nathan, M., Shekar, P., Couper, G., Rizzo, R., and Cohn, L.H. Hypothermic circulatory arrest enables aortic valve replacement in patients with unclampable aorta. (discussion 16867) Ann Thorac Surg. 2005; 80: 1679-1686 Gillinov, A.M., Lytle, B.W.,

[14] Gammie JS, Zhao Y, Peterson ED, O’Brien SM, Rankin JS, Griffith BP. J. Maxwell Chamberlain Memorial Paper for adult cardiac surgery: less-invasive mitral valve oper- ations: trends and outcomes from the Society of Thoracic Surgeons Adult Cardiac Surgery Database. Ann Thorac Surg 2010; 90: 1401-10.

[15] Condello I, Nasso G, Fiore F, et al. Fibonacci's golden ratio-an innovative approach to the design and management of extracorporeal circulation. Surg Technol Int. 2019 Feb 27; 34.

[16] Borrelli U, Al-Attar N, Detroux M, et al. Compact extracorporeal circulation: Reducing the surface of cardiopulmonary bypass to improve outcomes. Surg Technol Int. 2007; 16: 159-66. 